\title{
Hypereosinophilia in hodgkin lymphoma
}

\author{
Sanju Cyriac $\cdot$ T. G. Sagar $\cdot$ Rejiv Rajendranath $\cdot$ Krishnakumar Rathnam
}

Received: 16 February 2008 / Accepted: 14 April 2008

\begin{abstract}
The incidence of eosinophilia in Hodgkin lymphoma is approximately $15 \%$. Both peripheral and tissue eosinophilia have been noted in Hodgkin lymphoma. Eosinophils have important role in pathobiology of Hodgkin lymphoma. The mechanism of eosinophilia remains unknown though various mediators like IL-5 and GM-CSF have been implicated. We present a case who was diagnosed to have Hodgkin lymphoma and hypereosinophilia.
\end{abstract}

Keywords Hypereosinophilia $\cdot$ Hodgkin lymphoma

S. Cyriac $\cdot$ T. G. Sagar · R. Rajendranath · K. Rathnam

Cancer Institute,

Adyar, Chennai

S. Cyriac $(\bowtie)$

e-mail: drsanpan80@yahoo.com

\section{Case report}

A 9-year-old child presented to our institution with swelling in the left side of neck and intermittent fever of three months duration. No history of bleeding manifestations. He had dry cough. Physical examination revealed generalized lymphadenopathy and hepatosplenomegaly. He also had features of superior venacaval obstruction (SVCO). His investigations revealed Hemoglobin of $9.4 \mathrm{~g} / \mathrm{dl}$, total count of 1.8 lakhs $/ \mathrm{mm}^{3}$ and platelets of 2.94 lakhs $/ \mathrm{mm}^{3}$. Differential count showed Neutrophils 9\%, Lymphocytes $12 \%$ and Eosinophils $79 \%$. ESR was $50 \mathrm{~mm} / \mathrm{hr}$. Chest X ray showed mediastinal widening, diffuse pulmonary infiltrates. Bone marrow examination revealed hypercellular marrow with marked eosinophilic proliferation. Superior mediastinal adenopathy, bilateral pleural effusion and patchy bilateral pulmonary infiltrates were seen in CT thorax. CT Abdomen showed large retroperitoneal adenopathy.

Lymph node biopsy after immunohistochemical correlation was diagnostic of Hodgkin lymphoma - mixed cellularity. Patient was initiated on ABVD chemotherapy. The total count normalised to $9000 / \mathrm{mm}^{3}$ and Eosinophilia decreased to $20 \%$ after the very first cycle of chemotherapy. Patient is being continued on treatment.

\section{Discussion}

The incidence of eosinophilia in Hodgkin's disease is around $15 \%$ [1]. Hodgkin lymphoma in paediatric population, especially in the first decade is very rare. Among these patients male preponderence has been noticed. The most common histology noticed is mixed cellularity in the younger population [2]. 


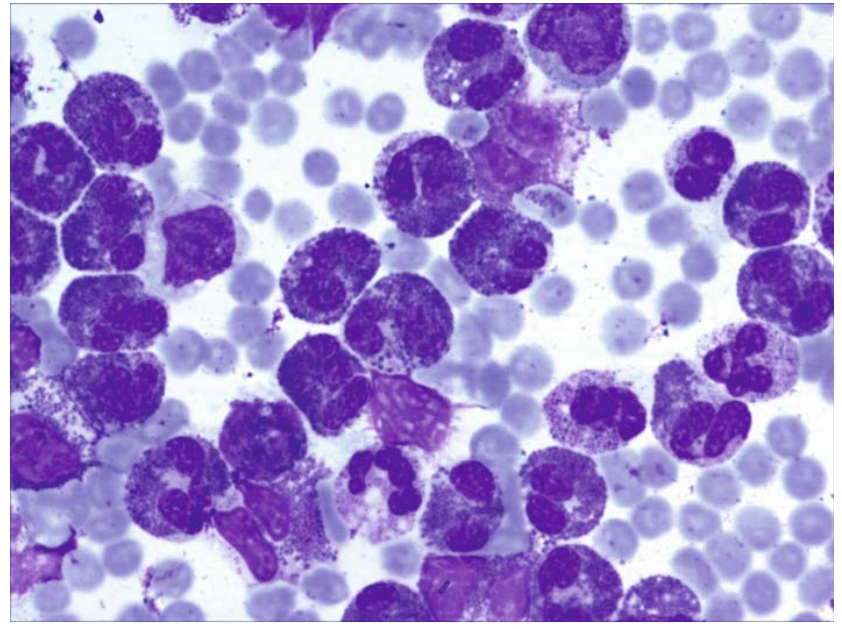

Fig. 1 Peripheral blood smear showing eosinophilia

The role of eosinophils in the pathobiology of Hodgkin's disease has been proved unequivocally. It has been suggested that eosinophils may act as important elements in the pathology of Hodgkin's disease by providing cellular ligands for TNF-super family receptors (CD40, CD30, CD95/Fas) are able to transduce proliferation and anti apoptotic signals on the surface of Reed Sternberg cells [3].

Eosinophilia has been proposed as one of the prognostic factors for Hodgkin's disease. The BLNI study showed that eosinophilia as a part of leukocytosis was associated with a minor survival advantage. But the survival advantage for patients with selective eosinophilia was highly significant [1]. In a Venezuelan study they found poor relapse free survival in eosinophilic group but with a better overall survival especially in stage IIIB/IV [4].
The German Hodgkin's lymphoma study group had shown that the proportion of eosinophil-rich cases was similar between the Nodular Sclerosis (NS) and Mixed Cellularity (MC) cases. But the clinical significance of eosinophilia was different between these histopathologic categories. Eosinophilia in Hodgkin lymphoma involved lymph nodes was of prognostic relevance in the NS cases, whereas in $\mathrm{MC}$ cases, the effect on survival, if any, was weaker $[5[$.

Although leucocytosis can occur in Hodgkin's disease, a total count of $1.8 \mathrm{lacs} / \mathrm{mm}^{3}$ with $79 \%$ eosinophils has not been reported. This case emphasizes that extreme eosinophilia can be a part of Hodgkin lymphoma.

\section{References}

1. Vaughan Hudson B, Linch DC, Macintyre EA et al (1987) Selective peripheral blood eosinophilia associated with a survival advantage in Hodgkin's disease. J Clin Pathol 40: 1246-1249

2. Mellisa M. Hudson, Michaela Onciu, Sarah S. Donaldson Hodgkin Lymphoma. In Philip A Pizzo, David G Poplack (eds) Principles and Practice of Paediatric Oncology. Lippincott Williams \& Wilkins, pp 695-696

3. Pinto A, Aldinucci D, Gloghini A, Zagonel V (1997) The role of eosinophils in the pathobiology of Hodgkin's disease. Ann Oncol 8 Suppl 2:89-96

4. Desenne JJ, Acquatella Stern R, Muller A, Sanchez M, Somoza R (1992) Blood eosinophilia in Hodgkin's disease: a follow up of 25 cases in Venezuela. Cancer 69:1248

5. Von Wasielewski R, Seth S, Franklin J, Fischer R, Hübner K, Hansmann ML, Diehl V and Georgii A (2000) Tissue eosinophilia correlates strongly with poor prognosis in nodular sclerosing Hodgkin's disease, allowing for known prognostic factors. Blood 95:1207-1213 